\title{
APRESENTAÇÃO
}

PRESENTATION

\section{MOBILIDADES E FRONTEIRAS: PERSPECTIVAS ANTROPOLÓGICAS FEMINISTAS PARA UMA MIRADA INTERSECCIONAL}

\author{
Natália Corazza Padovani (Universidade Estadual de Campinas) \\ Angela Facundo Navia (Universidade Federal do Rio Grande do Norte) \\ Camila Esguerra Muelle (Universidade Nacional da Colômbia)
}

Em texto publicado no dossiê Desdobramentos do feminismo, dos Cadernos Pagu de 2001, Mariza Corrêa descreve sua experiência pessoal como ativista e pesquisadora feminista brasileira de modo a, por meio dela, contar ao leitor sobre os desdobramentos que partiram da "teoria feminista" para a produção dos "estudos de gênero" no Brasil.

O texto remete a uma fala que Mariza Corrêa fez em Portugal. Não por acaso, a autora analisa a produção da figura de Carmem Miranda como símbolo nacional brasileiro das décadas de 1930 e 1940. Por meio da personagem da cantora portuguesa "branca como um fantasma", a autora demonstra que, em meio a processos de embranquecimento da "raça nacional", aliados às produções de exotização e erotização do corpo da "mulher brasileira", Carmem Miranda passa a ser "definida na Europa como a cor de café com leite da América” (CORRÊA, 2001, p. 28). É através dessa imagem que a antropóloga feminista chama atenção para como raça, sexo, gênero produzem efeitos de naturalização e biologização de corpos e nações os quais são, contudo, relacionais e políticos.

As ponderações de Corrêa fazem entrever que as análises sobre mobilidades e fronteiras, internacionais ou não, são melhor entendidas quando seus objetos de investigação e suas bases teóricas são construídos desde os arcabouços das teorias feministas e dos estudos de gênero. Afinal, aos sujeitos em trânsito são atribuídas, bem como são por eles articuladas (PISCITELLI, 2008), categorizações das diferenças que os localizam social e geopoliticamente de acordo com países do sul, do norte, do "terceiro mundo", ou ainda, como adequados ou ameaçadores para as ordens sociais das "democracias sexuais brancas" (FASSIN, 2012).

Inúmeras autoras feministas de diversos campos do saber demonstraram que "os nacionalismos têm gênero" (MCCLINTOCK, 2010, p. 517). Cynthia Enloe (1990), por exemplo, articulou a expressão marco da segunda onda feminista, " "o pessoal é político", ao argumento de que "o pessoal é internacional", evidenciando que as políticas de segurança nacional e táticas de guerra (dentre as quais o estupro) são atravessadas por gênero. Os argumentos que Enloe tece desde o léxico das relações internacionais e das ciências políticas são cabalmente demonstrados 
pela etnografia da antropóloga Veena Das (1995) e pelo relato pessoal em estreita vinculação com a historiografia macrossocial da socióloga Grace Cho (2008).

As autoras acima citadas são referência do impacto teórico feminista no campo dos estudos sobre política internacional, bem como de seus desdobramentos para as análises sobre transnacionalidades dos fluxos migratórios. Deve-se destacar que seus argumentos demonstram empiricamente que atributos de gênero, e mais particularmente as mulheres, configuram sujeitos e objetos por meio dos quais fronteiras nacionais são produzidas. Ou seja, as mulheres são simbolicamente incorporadas na política nacional como suas fronteiras (MCCLINTOCK, 2010; SEGATO, 2005).

No bojo da relação entre produção de fronteiras nacionais e mobilidades, o campo que se convencionou chamar de "feminismos transnacionais" (GREWAL; KAPLAN, 1994) dá um salto analítico significativo. As fronteiras passam a ser entendidas como escalas relacionais de classe, raça e gênero que podem ser vivenciadas independentemente de deslocamentos migratórios. Fronteiras, nesse registro, são compreendidas enquanto parte das experiências que constituem os sujeitos, e seus atravessamentos apenas podem ser analisados relacionalmente. Tal percepção relacional é também descrita por autoras localizadas no âmbito dos feminismos decoloniais, pós-coloniais e dos feminismos negros, ${ }^{2}$ tanto estadunidenses como brasileiros.

A fronteira de que fala a autora chicana Gloria Anzaldúa (1987), por exemplo, se materializa nos Estado-nacionais, patentemente produzidos pelos sangrentos empreendimentos de guerras coloniais. Por outro lado, la frontera é habitada territorial e subjetivamente. A fronteira é o centro das relações, é o marco desde onde a linguagem e o léxico da inteligibilidade da vida é tramado cotidianamente, nunca um espaço vazio. Não por acaso, por meio de sua escrita, Anzaldúa enreda um idioma mestizo que não pode ser traduzido para o Inglês, para o Espanhol ou para qualquer outro encapsulamento normativo nacional. Antes, propõe uma epistemologia desde a própria gramática fronteiriça, proposta também densamente elaborada por Lélia Gonzalez (1984).

O pretuguês, de que fala a antropóloga, é um idioma da diáspora ${ }^{3}$ elaborado nas teias da colonização de um território que não pode ser vivenciado somente pelo desterro do continente africano - e daí a crítica da autora ao uso da categoria "afro-americano" e a autores panafricanistas (GONZALEZ, 1984) - mas também pelos embates embevecidos no terror colonial latino-americano (TAUSSIG, 1993). É o pretuguês de Lélia Gonzalez, assim como a escrita mestiza de Anzaldúa, forjado no bojo da violência brutal da escravidão e dos racismos, que permite, ao mesmo tempo, resistir a esses. São idiomas que centralizam em seus léxicos as diásporas e mobilidades dos embates coloniais e, assim, desbundam fronteiras das diferenças que deles decorrem. ${ }^{4}$ 
É justamente no desdobramento da centralidade dos estados-nações para os deslocamentos através de suas fronteiras, como processos de sujeição e de subjetivação, que Inderpal Grewal e Caren Kaplan (1994) localizam a passagem dos estudos pós-coloniais para os transnacionais. Nesse âmbito, o termo transnacional é utilizado ao invés de internacional, com vistas a refletir a necessidade de desestabilizar mais do que manter as fronteiras nacionais, de raça e de gênero. Segundo Grewal e Kaplan, enquanto a noção de internacional refere-se à soberania dos estados-nações, o arcabouço transnacional permite que as assimetrias e desigualdades sejam analisadas desde as práticas de subversão e agência dos sujeitos que atravessam as fronteiras. Para as autoras, teorias e metodologias pós-coloniais viabilizaram os estudos transnacionais através do adensamento dos conceitos de subalternidade, diáspora e as "escritas de viagens" - que têm em James Clifford (2007), mas também na própria Caren Kaplan (1996) algumas das principais referências. Esses conceitos tornaram possível compreender que os sujeitos em deslocamento produzem relações transnacionais. Ou seja, vivenciam relações através das fronteiras, mais do que através dos estados-nacionais. De tal modo que o próprio deslocamento é visto como um processo necessariamente multissituado, afinal, os deslocamentos de pessoas também são deslocamentos de ideias, subjetividades, representações e objetos de consumo, como bem nos lembra Arjun Appadurai (1986).

Os sentidos atribuídos às mobilidades transnacionais, portanto, são inescapavelmente embebidos pelas intersecções de atributos como gênero, raça, classe, nacionalidade, geração, sexualidade. Categorizações de diferenciação que não aparecem como formas exclusivamente limitantes ou excludentes e de sobreposição de opressões, mas que, assim como as fronteiras, oferecem simultaneamente à produção de assimetrias recursos que possibilitam a ação e a agência (PISCITELLI, 2008).

Os caminhos analíticos propostos por autoras feministas de diversos campos têm permitido, como vimos, desestabilizar noções como centro-periferia e local-global. Nesse sentido, as análises das autoras discutidas acima fazem eco nas críticas contemporâneas às políticas humanitárias e de controle das fronteiras tecidas no âmbito dos estudos sobre as figuras do "refúgio", da "migração", do "tráfico de pessoas" e do "crime organizado". Categorias que dizem muito e muito pouco ao mesmo tempo e que não levam em conta as possibilidades de articulações das pessoas em deslocamento através das margens ou da descolonização das assimetrias estatais e nacionais.

Ao propor reunir artigos que desenvolvam análises sobre mobilidades desde perspectivas antropológicas de gênero, sexualidade e suas intersecções, o presente dossiê estabelece franca interlocução com o vasto campo da literatura feminista sobre fronteiras das diferenças. Nesse sentido, os artigos aqui reunidos, mais do que explorarem as mobilidades através das fronteiras de Estado-nação, se voltam para regimes de 
mobilidades - e logo de imobilidades (GLICK-SCHILLER; SALAZAR, 2012) - cartografados desde os complexos relevos das geografias de poder (MAHLER; PESSAR, 2001) que localizam e desestabilizam sujeitos das/nas fronteiras.

Antes de dar seguimento a esta apresentação, cabe sublinhar mais uma vez que as fronteiras sobre as quais se voltam os artigos deste dossiê não são exclusivamente referenciadas pelos contornos das mobilidades entre diferentes países. Vale lembrar aqui que pesquisas de referência para o desenvolvimento das antropologias e sociologias urbanas também vêm chamando atenção para a produção de zonas morais de sociabilização e consumo na cidade que criminalizam deslocamentos por entre seus territórios.

Trabalhos como os de Nestor Perlonguer (1987), por exemplo, impactaram os estudos das cidades ao demonstrarem que circuitos e deslocamentos são produzidos por produtores de fronteiras que localizam e diferenciam os sujeitos através das categorizações de sexualidade, gênero, raça e classe as quais fazem emergir ou encerram campos de possibilidades e de mobilidades em topografias variavelmente marcadas pelas moralidades impressas nos corpos e práticas daqueles que por ali circulam. Tais territórios, entretanto, não são necessariamente mensuráveis geograficamente. Antes, as fronteiras são constituídas pelas relações que produzem circuitos através dos quais deslocamentos são negociados, construídos e disputados. Tais disputas, guerras e negociações, como lembra Gabriel Feltran (2011), estão profundamente calcadas nas tensões ou embaralhamentos estabelecidos entre formas de mercados e trabalhos legais e ilegais. Se Nestor Perlonguer chamava atenção para o "negócio do michê" e os ilegalismos que eram a ele vinculados, os estudos sobre periferias e prisões têm evidenciado que a criminalização dos mercados de drogas refere-se, antes, aos processos de criminalização dos pobres, dos negros, das prostitutas, das travestis: das classes perigosas. É sobre essa fina relação entre regimes de mobilidades e deslocamentos através das fronteiras dos territórios das cidades que recaem as primorosas análises de Bela Feldman-Bianco (2016), ${ }^{6}$ as quais permitem visibilizar alinhavos de processos de violência e deslocamentos forçados, migrações e atravessamentos urbanos.

A proposta deste dossiê é tributária das produções citadas acima, que permitiram, dentre outras coisas, implodir as fronteiras do campo dos estudos migratórios, fazendo transbordar criativamente os usos das ferramentas analíticas propostas pelos regimes de mobilidades. É o que fazem os textos de Natália Ferreira Gonçales e Montserrat Valle; de Roberta Alves Silva, Rafael Pereira Santos e André Rodrigo Rech; bem como o ensaio de Telma de Sousa Bemerguy publicados neste número. Os artigos de Alexandre Branco Pereira; de Lucia Sestokas; de Jullyane Carvalho Ribeiro e de Mirian Alves de Souza também articulam analítica e etnograficamente fronteiras das diferenças. Essas, agora, indaga- 
das com vistas aos processos de construção das categorias estatais e de governamentalidade que, pelos escrutínios das trajetórias, vestimentas, narrativas e idiomas, categorizam sujeitos como "perigosos"; "dominados" "autistas"; "vulneráveis" ou, ainda, como aqueles que corporificam a "crise migratória". Sujeitos que materializam as próprias fronteiras nacionais em suas (i)mobilidades.

Os textos aqui reunidos para a Revista Vivência, por meio de instigantes pesquisas de mestrado e doutorado recentemente concluídas, ou ainda em andamento, contribuem para o desenvolvimento do campo de saber sobre mobilidades, o qual está intrinsecamente relacionado com os estudos de gênero e as teorias feministas, como tentamos demonstrar nesta breve apresentação.

O presente dossiê é, ainda, resultado de uma parceria estabelecida entre as suas organizadoras. ${ }^{7}$ Uma parceria profissional afetiva, cunhada por entre fronteiras nacionais e regionais, pelas geografias de poder que desafiam as produções científico-acadêmicas nos Estados de um Sul global muito específico, o das nossas lat(d)inidades.

Boa leitura!

\section{NOTAS}

1. Uma maior complexificação das definições de "ondas do feminismo" pode ser vista em Rowbotham (2014).

2. Para uma discussão sobre feminismos pós-coloniais e decoloniais ver Ballestrin, 2017.

3. Para Avtar Brah (1996), diásporas são vistas em termos genealógicos, no sentido de produzirem o efeito de historicidade de diferentes trajetórias e mobilidades, as quais são analisadas de modo a colocarem em relação contextos políticos, afecções sociais, subjetividades e identidades nacionais. Cabe destacar que a autora tem sua trajetória marcada por deslocamentos diaspóricos. Brah nasceu na Índia e cresceu em Uganda, de onde fugiu com a família antes do processo de expulsão dos asiáticos do país na década de 1970. Sua definição de diáspora alude, portanto, a como os deslocamentos dão sentido e historicidade às trajetórias dos sujeitos em trânsito. Ou seja, mais do que repousada em uma identidade nacional, a produção de subjetividades, bem como de subjetivações, é compreendida desde processos de deslocamento, desde as próprias diásporas e desde os atravessamentos das fronteiras. Cabe ainda destacar que as cartografias da diáspora de Avtar Brah estão bastante alinhavadas às análises de Paul Gilroy sobre o Atlântico Negro (1993). Formulação analítica balizada nos deslocamentos forçados transatlânticos sobre as quais se volta, também, Beatriz Nascimento em suas várias escritas sobre a diáspora africana, reunidas recentemente em livro (2018).

4. Poderíamos desenvolver ainda muito mais a discussão sobre feminismos e fronteiras da diferença, a qual não necessariamente se vale de mobilidades transnacionais. Tal debate, contudo, não cabe no espaço desta apresentação. Indicamos, portanto, as leituras valorosas de autoras que costuram as tramas dos saberes feministas nas fronteiras das diferenças e no deslocamento das pers- 
pectivas epistêmicas desde os campos dos feminismos negros estadunidense, particularmente, como é o caso de Bell Hooks (2019) e Audre Lorde (1993). Ademais, cabe indicar o texto de Angela e Onika Gilliam (1995) escrito na passagem dos anos compartilhados por mãe e filha norte-americanas, negras, em mobilidade nos territórios brasileiros urbanos da ditadura militar e de fins do século XX.

5. Sobre as figuras do "refúgio", "da "migração", do "tráfico de pessoas" e do "crime organizado", sugerimos ver: Malkki, 1995; Facundo Navia, 2017; Piscitelli, 2013; Sudbury, 2005; Padovani, 2020.

6. Sugerimos fortemente, ainda, os seguintes artigos publicados ao longo deste ano de 2020: Feldman-Bianco; Domenech e Sanjurjo, 2020; Feldman-Bianco, Sanjurjo e Silva, 2020.

7. De todos nossos espaços de afeto e trocas produtivas de saber antropológico, vale destacar o nosso agradecimento ao Comitê Migrações e Deslocamentos da Associação Brasileira de Antropologia (ABA), do qual Angela Facundo Navia e Natália Corazza Padovani são integrantes, junto com pesquisadores e docentes de especial relevância para a elaboração destas linhas. Agradecemos à Bela Feldman-Bianco; Igor José de Renó Machado; Adriana Piscitelli; Denise Fagundes Jardim; Liliana Sanjurjo e Márcia Anita Sprandel.

\section{REFERÊNCIAS}

ANZALDÚA, Glória. Bordelands/La Frontera: The New Mestiza. San Francisco: Spinters/Aunt Lute, 1987.

APPADURAI, Arjun. The social life of things: commodities in cultural perspective. Cambridge: Cambridge University Press, 1986.

BALLESTRIN, Luciana Maria de Aragão. Feminismos Subalternos. Revista de Estudos Feministas, v. 25, n. 3, p. 1035-1054, 2017. Disponível em: <http://dx.doi.org/10.1590/1806-9584.2017v25n3p1035>. Acesso em: 12 dez. 2020.

BRAH, Avtar. Cartographies of diaspora: Contesting identities. London: Routledge, 1996.

CHO, Grace. Haunting the Korean Diaspora: Shame, secrecy and the forgotten war. Minneapolis: University of Minnesota Press, 2008.

CLIFFORD, James. Routes: travel and translation in the twenthieth century. Massachusetts: Harvard University Press, 2007.

CORRÊA, Mariza. Do feminismo aos estudos de gênero no Brasil: um exemplo pessoal. Cadernos Pagu, Campinas, n. 16, p. 13-30, 2001.

DAS, Veena. Critical Events: An Anthropological Perspective on Contemporary India. New Delhi: Oxford University Press, 1995.

ENLOE, Cynthia. Bananas, Beaches and Bases: making feminist sense of international politics. Berkeley and Los Angeles: University of California Press, 1990.

FACUNDO NAVIA, Angela. Êxodos, refúgios e exílios. Rio de Janeiro: Papéis Selvagens, 2017. 
FASSIN, Eric. Sexual Democracy and the New Racialization of Europe. Journal of Civil Society, v. 8, Special Issue 3: Changing the Debate on European Social Space, 2012. Disponível em: <https://doi.org/10.1080/ 17448689.2012.738887 >. Acesso em: 12 dez. 2020.

FELDMAN-BIANCO, Bela. Desarrollos de la perspectiva transnacional: Migración, ciudad y economía política en la intersección de la antropología y la historia. In: BESSERER, F. (Org.). Intersecciones Urbanas: Ciudad Transnacional, Ciudad Global. Ciudad de México: Editorial UAM, 2016. p. 57-86. (Colección Estudios Transnacionales).

FELDMAN-BIANCO, Bela; DOMENECH, Eduardo; SANJURJO, Liliana. Desplazamientos, desposesión y violencias. Historia y Sociedad, Medellín, Universidad Nacional de Colombia, p. 7-23, jul./dez. 2020.

FELDMAN-BIANCO, Bela, SANJURJO, Liliana; SILVA, Douglas Mansur da. Migrações e deslocamentos: balanço bibliográfico da produção antropológica brasileira entre 1940 e 2018. In: BIB - Revista Brasileira de Informações Bibliográficas em Ciências Sociais, São Paulo, n. 93, 2020. Disponível em: <https://doi.org/10.17666/bib9309/2020>. Acesso em: 12 dez. 2020.

FELTRAN, Gabriel. Fronteiras de tensão: política e violência nas periferias de São Paulo. São Paulo: EdUNESP/CEM/CEBRAP, 2011.

GILLIAM, Angela; GILLIAM, Onik’a. Negociando a subjetividade de mulata no Brasil. Revista Estudos Feministas, Florianópolis, v. 3, n. 2, p. 525, jan. 1995.

GILROY, Paul. The Black Atlantic: Modernity and Double Consciousness. Cambridge, Massachusetts: Harvard University Press and Verso Books, 1993.

GLICK SCHILLER, Nina; SALAZAR, Noel B. Regimes of mobility across the globe. Journal of Ethnic and Migration Studies, v. 39, n. 2, p. 183-200, 2012. Disponível em: <https://doi.org/10.1080/1369183X.2013.723253 >. Acesso em: 12 dez. 2020.

GONZALEZ, Lélia. Racismo e sexismo no Brasil. Revista Ciências Sociais Hoje, Anpocs, p. 223-244, 1984.

GREWAL, Inderpal; KAPLAN, Caren (Eds.). Scattered Hegemonies: Postmodernity and Transnational Feminist Practices. Minneapolis: University of Minnesota Press, 1994.

HOOKS, Bell. Teoria feminista: Da margem ao centro. São Paulo: Perspectiva, 2019.

KAPLAN, Caren. Questions of Travel: Postmodern Discourses of Displacement. Durham: Duke UP, 1996.

LORDE, Audre. Zami Sister Outsider Undersong. Nova York: Quality Paperback Book Club, 1993.

MAHLER, Sarah J.; PESSAR, Patricia R. Gendered Geographies of Power. Identities: Global Studies in Culture and Power, n. 7, p. 441-59, 2001. 
MALKKI, Liisa. Purity and exile: violence, memory, and national cosmology among Hutu refugees in Tanzania. Chicago: University of Chicago Press, 1995.

McCLINTOCK, Anne. Couro imperial: Raça, gênero e sexualidade no embate colonial. Trad. Plínio Dentzien. Campinas: Editora da Unicamp, 2010.

MOHANTY, Chandra. Under Western Eyes Revisited: Feminist Solidarity through Anticapitalist Struggles. Sings, v. 28, n. 2, p. 499-535, 2003. NASCIMENTO, Beatriz. Beatriz Nascimento, quilombola e intelectual: Possibilidades nos dias da destruição. São Paulo: Filhos da África, 2018. PADOVANI, Natália Corazza. ¿Todas las mujeres acusadas de tráfico internacional de drogas son víctimas de trata de personas?: Género, clase, raza y nacionalidad en los discursos sobre crimen organizado en Brasil. In: DAICH, Deborah; VARELA, Cecilia (Orgs.). Los feminismos en la encrucijada del punitivismo. Buenos Aires: Biblo, 2020. p. 367-436. PERLONGER, Néstor Osvaldo. O Negócio do Michê: a prostituição viri. São Paulo: Editora Brasiliense, 1987.

PISCITELLI, Adriana. Interseccionalidades, categorias de articulação e experiências de migrantes brasileiras. Sociedade e Cultura, v. 11, n. 2, jul./dez. 2008.

PISCITELLI, Adriana. Trânsitos: brasileiras nos mercados transnacionais do sexo. Rio de Janeiro: EdUERJ, 2013.

ROWBOTHAM, Sheila. Women, Resistence and Revolution: A History of Women and Revolution in the Modern Word. London; New York: Verso, 2014.

SEGATO, Rita Laura. Território, soberania e crimes de segundo Estado: a escritura nos corpos das mulheres de Ciudad Juárez. Estudos Feministas, Florianópolis, v. 13, n. 2, p. 256, maio/ago. 2005.

SUDBURY, Julia. Global Lockdown: Race, Gender, and the Prison-Industrial Complex. New York; London: Routledge, 2005.

TAUSSIG, Michael. Xamanismo, colonialismo e o homem selvagem: um estudo sobre o terror e a cura. Rio de Janeiro: Paz e Terra, 1993 [1987]. 